\title{
Lumbar Interspinous Process Fixation and Fusion with Stand-Alone Interlaminar Lumbar Instrumented Fusion Implant in Patients with Degenerative Spondylolisthesis Undergoing Decompression for Spinal Stenosis
}

\author{
Franco Postacchini ${ }^{1}$, Roberto Postacchini ${ }^{2}$, Pier Paolo Maria Menchetti ${ }^{3}$, \\ Pasquale Sessa ${ }^{1}$, Michela Paolino ${ }^{1}$, Gianluca Cinotti ${ }^{1}$ \\ ${ }^{I}$ Department of Saimlal, Section of Orthopedic Surgery, Clinica Ortopedica, Università Sapienza, Rome, Italy \\ ${ }^{2}$ Ospedale Israelitico, Rome, Italy \\ ${ }^{3}$ Rome American Hospital, Rome, Italy
}

\section{Study Design: Prospective cohort study.}

Purpose: To assess the ability of a stand-alone lumbar interspinous implant (interspinous/interlaminar lumbar instrumented fusion, ILIF) associated with bone grafting to promote posterior spine fusion in degenerative spondylolisthesis (DS) with vertebral instability. Overview of Literature: A few studies, using bilateral laminotomy (BL) or bilateral decompression by unilateral laminotomy (BDUL), found satisfactory results in stenotic patients with decompression alone, but others reported increased olisthesis, or subsequent need for fusion in DS with or without dynamic instability.

Methods: Twenty-five patients with Grade I DS, leg pain and chronic low back pain underwent BL or BDUL and ILIF implant. Olisthesis was $13 \%$ to $21 \%$. Follow-up evaluations were performed at 4 to 12 months up to 25 to 44 months (mean, 34.4). Outcome measures were numerical rating scale (NRS) for back and leg pain, Oswestry disability index (ODI) and short-form 36 health survey (SF-36) of body pain and function.

Results: Fusion occurred in 21 patients (84\%). None had increased olisthesis or instability postoperatively. Four types of fusion were identified. In Type I, the posterior part of the spinous processes were fused. In Type II, fusion extended to the base of the processes. In Type III, bone was present also around the polyetheretherketone plate of ILIF. In Type IV, even the facet joints were fused. The mean NRS score for back and leg pain decreased by $64 \%$ and $80 \%$, respectively. The mean ODI score was decreased by $52 \%$. SF-36 bodily pain and physical function mean scores increased by $53 \%$ and $58 \%$, respectively. Computed tomography revealed failed fusion in four patients, all of whom still had vertebral instability postoperatively.

Conclusions: Stand-alone ILIF with interspinous bone grafting promotes vertebral fusion in most patients with lumbar stenosis and unstable Grade I DS undergoing BL or BDUL.

Keywords: Lumbar spine; Degenerative spondylolisthesis; Lumbar stenosis; Laminotomy; Interspinous fusion

Received May 10, 2015; Revised Jun 22, 2015; Accepted Jun 27, 2015

Corresponding author: Roberto Postacchini

Ospedale Israelitico, Piazza S. Bartolomeo all' Isola 21, 00186, Rome, Italy

Tel: +39-33-8135-1061,, Fax: +39-06-6558-9329, E-mail: robby1478@hotmail.com 


\section{Introduction}

Surgical management of degenerative spondylolisthesis (DS) consists of decompression of the neural structures or decompression and fusion of the involved motion segment. The latter procedure is mostly performed in the presence of leg symptoms and significant back pain when the slipped vertebra is unstable (i.e., when it exhibits a change in translational and/or angular motion on flexion-extension radiographs) [1]. The current methods of vertebral fusion are posterolateral fusion, posterior lumbar interbody fusion (PLIF), transforaminal lumbar interbody fusion (TLIF), and extreme lateral interbody fusion associated with pedicle-screw instrumentation. These modalities have several drawbacks. They may be challenging, which can increase both the operative time and the risk of serious complications [2,3]. Furthermore, the increased stiffness of the fused motion segment may cause overloading at adjacent motion segments with possible induction or worsening of degenerative changes $[4,5]$. These drawbacks led to the development of minimally invasive devices to stabilize adjacent spinous processes with the aim of decreasing both the morbidity of the pediclescrew instrumentation and/or the interbody fusion, and the overload on adjacent vertebral levels.

Recently, three implants have been introduced to perform interspinous process stabilization and fusion. The first were the SPIRE (Medtronic Sofamor Danek, Memphis, TN, USA) and the Aspen (Lanx, Broomfield, CO, USA) models. The former was the subject of a clinical study on a cohort of patients including a limited number of cases with DS, in whom the implant was used to supplement a PLIF. The clinical results were mostly satisfactory [6], but it is unclear whether the improvement should be ascribed to the interbody fusion. The Aspen model has been evaluated in several biomechanical investigations $[7,8]$, but only one clinical study [9] aimed at assessing the prevalence of spinous process fracture in patients, treated with X-STOP, and a few with stand-alone Aspen.

The interspinous/interlamina lumbar instrumented fusion (ILIF; Nuvasive, San Diego, CA, USA) is a device introduced for interspinous/interlaminar fusion. This device was evaluated in a biomechanical study [10] comparing the stabilizing effect of the implant with that of pediclescrew instrumentation. A single clinical study [11] was performed on 16 patients with lumbar stenosis undergoing open decompression associated to stand-alone ILIF; none of the subjects had DS.

The primary aim of this prospective study was to assess the ability of stand-alone ILIF to promote posterior spine fusion in stenotic patients showing Grade I DS with dynamic instability of the slipped vertebra treated with open decompression. Another goal was to provide initial data on the clinical value of the implant in this pathologic condition

\section{Materials and Methods}

Between January 2010 and September 2012, 42 patients with Mayerding Grade I DS who had lumbar stenosis and chronic radicular pain underwent surgical management. The ILIF was implanted in 26 patients, who represented the study group. The inclusion criteria were DS at a single level, instability of the slipped vertebra, bilateral leg pain even if more severe on one side, chronic low back pain continuous or frequent, unilateral leg symptoms with bilateral severe stenosis and/or severe chronic back pain. Exclusion criteria were indication for bilateral laminectomy, absence of vertebral instability with no consequent need of fusion, unilateral leg pain with moderate stenosis and occasional back pain in which only decompression was mostly done, severe osteoporosis (T-score of 2.5), or anatomical variants that might make it impossible to implant the device. Previous surgery on the motion segment to be operated on also represented a criterion of exclusion because the scar tissue might hinder bony fusion. One patient was lost to follow-up, so that the study group consisted of 25 patients (17 females and eight males; mean age 64.8 years; range, $53-74$ years).

Decompressions in bilateral laminotomy (BL) or bilateral decompression by unilateral laminotomy (BDUL), performed using the operating microscope, were carried out in 16 and nine cases, respectively. Patients were operated in two different institutions by two surgeons each carrying out a single type of decompression. All patients gave informed consent. The research was performed following the Declaration of Helsinki principles.

Stenosis was diagnosed by magnetic resonance imaging in 22 cases and computed tomography (CT) in three cases. It was classified as central or lateral, and rated as mild, moderate, or severe [12]. All patients underwent plain radiographs in neutral standing position, and lateral standing flexion-extension radiographs of the lumbar spine. Slipping was calculated in millimeters [13], which were 
then converted into percentage of sagittal displacement of the lower endplate of the slipped vertebra compared to the upper endplate of the vertebra below. The angular displacement was measured in degrees between adjacent vertebral endplates. The vertebra was considered olisthetic when the slip was $\geq 8 \%$ [14]. Slipping was rated as mild or moderate when it did not exceed $12 \%$ or $16 \%$, respectively, and was ranked severe for higher percentages. The slipped vertebra was considered unstable if the change in translational motion on dynamic radiographs was $\geq 3 \%$ [15] or the angular motion $\geq 4^{\circ}[16]$. Translational or angular instability was arbitrarily rated as mild when the difference of slipping was $3 \%$ to $5 \%$, or the angular motion reached $5^{\circ}$ to $6^{\circ}$, moderate if the difference of olisthesis was $6 \%$ to $8 \%$ or the angular motion was $7^{\circ}$ to $9^{\circ}$, and severe when the values were greater. Based on postoperative anteroposterior radiographs and CT scans, the interspinous fusion was rated as "certain" when there was clear evidence that the spinous processes of adjacent vertebrae were connected by a solid, continuous bridge of bone or the facet joint were fused; "uncertain" if it was unclear whether a sound fusion had occurred; "incomplete" if there were areas of bone separated by zones with no new bone; and "absent" when there was no or almost no bone in the interspinous space.
Two spine surgeons and a radiologist expert in spine conditions, who were blind to the patients' clinical data, independently assessed the imaging studies for degrees of slipping and characteristics of fusion.

Preoperatively, information was obtained on the severity of back and leg pain and physical examination was performed by two independent orthopedists. The outcome measures were the numerical rating scale (NRS; ranging from 0 for no pain to 10 for very severe pain) for both low back and leg pain, the Oswestry disability index (ODI; a 100-point scale, with lower scores indicating less severe symptoms) and the 36-item short-form general health survey (SF-36) bodily pain and physical function (a 100-point scale, with higher scores indicating less severe symptoms).

\section{Surgical technique and operative data}

After neural decompression, the interspinous ligament was removed, the ends of the opposite processes were freed from the supraspinous ligament, and a small portion of the edge of each spinous process was excised to expose cancellous bone. Trial spacers of different widths were inserted in the interspinous space to select what best fitted the space (Fig. 1A). No attempt was made to distract
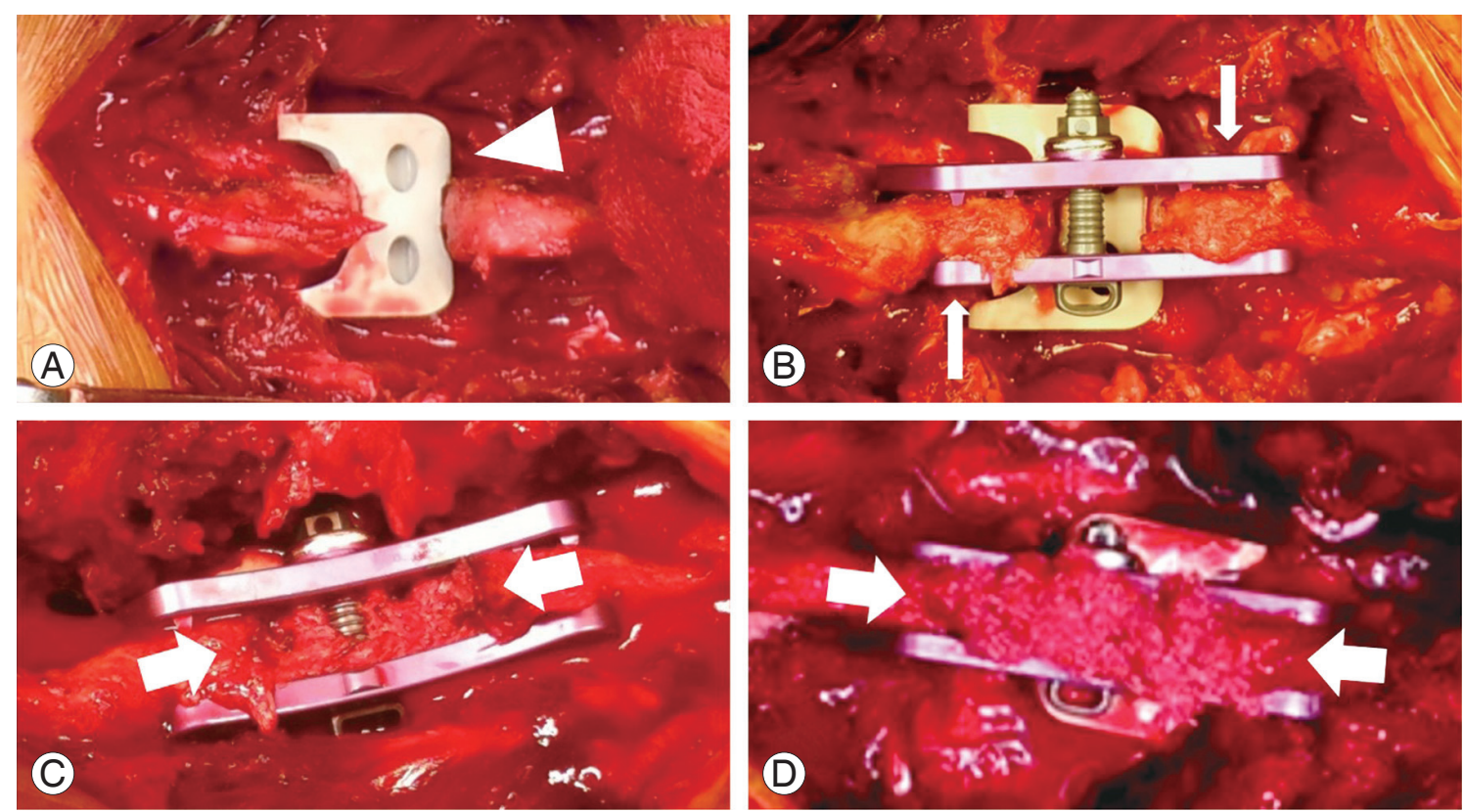

Fig. 1. Surgical technique of implantation of interlaminar lumbar interbody fusion (ILIF). (A) Trial spacer inserted between the spinous processes after excision of the interspinous ligament. (B) Definitive spacer in place, and lateral plates (white arrows) tightened and locked to the post. (C) Initial bone graft (white arrows) inserted between the lateral plates above the spacer. (D) Abundant bone graft added until the screw connecting the lateral plates is covered, and some graft placed over the end of the spinous processes (white arrows). 
the spinous processes. A definitive polyetheretherketone (PEEK) spacer was inserted and the lateral plates were applied and tightened (Fig. 1B). Bone graft was placed into the implant between the spinous processes (Fig. 1C). The bone was impacted against the spacer and some graft was placed over the end of the spinous processes (Fig. 1D). As a graft, we used the bone obtained from the laminoarthrectomy. If this was not enough, as occurred in four patients undergoing BDUL, cancellous bone was harvested from the iliac crest through a short skin incision.

The mean operating time for implantation of ILIF and bone grafting was 21 minutes (range, 13-25 minutes) with an estimated blood loss of $19.7 \mathrm{~mL}$ (range, 15-25 mL) when bone from laminoarthrectomy was used. In patients undergoing iliac bone harvesting, the respective values were 37.4 minutes (range, $25-45$ minutes) and $46.2 \mathrm{~mL}$ (range, $35-55 \mathrm{~mL}$ ).

\section{Follow-up assessment}

Follow-up evaluations were made at 4,7 , and 12 months after surgery, the last being performed at a mean of 34.4 months (range, 25-41 months). At each follow-up, all outcome measures were assessed. Plain radiographs were obtained at each follow-up and dynamic radiographs at 7 months and at the last follow-up. In 21 patients, CT was performed at the 7-month follow-up, whereas in four with uncertain or no fusion on radiographs it was carried out also 4 months after surgery.

\section{Statistical analyses}

The Lilliefors (Kolmogov-Smirnov) normality test was performed for all assessed variables. Mean, standard deviation and $95 \%$ confidence interval (CI) were computed for all variables. Wilcoxon signed rank sum test was used to evaluate the differences between preoperative and postoperative mean scores. Mann Whitney $U$ test was employed to assess the differences between fused and unfused patients. The level of significance was set at 0.05 for all assessed variables. Intraclass correlation coefficients (ICCs) were calculated to determine the intraobserver and interobserver agreement among the evaluators of imaging studies. Interobserver agreement was assessed using kappa statistics. IBM SPSS ver. 19.9 (IBM Co., Armonk, NY, USA) was used for statistical analysis.
Table 1. Preoperative imaging data

\begin{tabular}{lc} 
Variable & No. of cases \\
Involved level & \\
\hline L4-L5 & 20 \\
\hline L3-L4 & 5 \\
\hline Type of stenosis & \\
\hline Central & 20 \\
\hline Lateral & 5 \\
\hline Severity of stenosis & \\
\hline Mild & 7 \\
\hline Moderate & 10 \\
\hline Severe & 8 \\
\hline Slipping $\left(^{\circ}\right.$ ) & \\
\hline Mild & 6 \\
\hline Moderate & 17 \\
\hline Severe & 2 \\
\hline Translational motion (FE) & 8 \\
\hline Mild & 15 \\
\hline Moderate & 2 \\
\hline Severe & 0 \\
\hline Angular motion (FE) & \\
\hline Mild & \\
\hline Moderate & \\
\hline Severe & \\
\hline & \\
\hline
\end{tabular}

FE, flexion-extension.

\section{Results}

The combined ICCs for intraobserver and interobserver reliability were, respectively, 0.89 (95\% CI, $0.85-0.91)$ and 0.87 (95\% CI, 0.82-0.93), which indicates that assessment of the imaging studies by evaluators was sufficiently reliable. The mean value for kappa statistics among observers was 0.81 .

\section{Preoperative clinical data}

Only one vertebral level was involved in all cases and most had spondylolisthesis of L4 (Table 1). Nearly half of patients exhibited moderate stenosis, and the second group, in order of frequency, was that with severe stenosis. The amount of slipping ranged from $13 \%$ to $21 \%$ (mean, $16.2 \%)$ and was moderate in most cases and severe in two cases (Table 1). Dynamic translational instability was 
Table 2. Preoperative clinical characteristics

\begin{tabular}{lc} 
Characteristic & No. of cases \\
Low back pain & 14 \\
\hline Chronic.continuous & 11 \\
\hline Chronic frequent & \\
Leg pain & 7 \\
\hline Bilateral equal on both sides & 14 \\
\hline Bilateral more severe on one side & 4 \\
\hline Unilateral & \\
\hline Claudication & 17 \\
\hline Yes & 8 \\
\hline No & 21 \\
\hline Motor deficits & 3 \\
\hline None & 1 \\
\hline L5 unilateral & \\
\hline L4 unilateral &
\end{tabular}

moderate or mild in the majority of cases, and dynamic angular instability was present in two (Table 1). All patients complained of chronic back pain, that was continuous or frequent. In most cases leg pain was bilateral, but often was more severe on one side (Table 2). Five patients had unilateral leg symptoms in the presence of stenosis on both sides. Intermittent claudication was reported by 17 patients. Peripheral motor deficits were rarely observed (Table 2).

\section{Postoperative findings}

Anteroposterior radiographs taken at the 7-month followup showed a certain interspinous fusion in 15 cases and an uncertain or incomplete fusion in six and two patients, respectively, whereas in two patients no fusion was apparent (Table 3). Although we basically referred to the 7 -month radiographs, in many patients with certain fusion, even radiographs taken at 4 months suggested that fusion had occurred (Fig. 2). CT scans obtained at 7 months confirmed the presence of fusion in all patients with certain fusion on radiographs and showed that fusion had occurred in the six uncertain cases (Table 3). On CT scans obtained at both the 4- and 7-month follow-ups, one of the two cases with incomplete fusion had a largely incomplete fusion that was rated as absent, and the two patients with no fusion exhibited only scant bony fragments in the interspinous space. The second patient with incomplete
Table 3. Postoperative imaging data

\begin{tabular}{|c|c|}
\hline Variable & No. of cases \\
\hline \multicolumn{2}{|c|}{ Interspinous fusion } \\
\hline \multicolumn{2}{|c|}{ Anteroposterior radiograph } \\
\hline Certain & 15 \\
\hline Uncertain & 6 \\
\hline Incomplete & 2 \\
\hline Absent & 2 \\
\hline \multicolumn{2}{|c|}{ Computed tomography scan } \\
\hline Certain & 21 \\
\hline Incomplete & 1 \\
\hline Absent & 3 \\
\hline \multicolumn{2}{|l|}{ Olisthesis } \\
\hline Unchanged & 24 \\
\hline Increased & 1 \\
\hline \multicolumn{2}{|c|}{ Dynamic instability } \\
\hline \multicolumn{2}{|l|}{ Translational } \\
\hline No & 21 \\
\hline Mild & 2 \\
\hline Moderate & 1 \\
\hline Severe & 1 \\
\hline \multicolumn{2}{|l|}{ Angular } \\
\hline No & 21 \\
\hline Mild & 0 \\
\hline Moderate & 1 \\
\hline Severe & 0 \\
\hline
\end{tabular}

fusion at 4 months showed no change over time.

The 21 patients with fusion showed no increase in olisthesis. Of these patients, at baseline seven had mild and 13 had moderate dynamic translational instability, and one showed severe translational and moderate angular instability. At the final follow-up, no patients showed a change in translational or angular motion. On CT scans, four types of bony fusion were identified (Table 3). In Type I, the bone joined the posterior part of the spinous processes (Fig. 3). In Type II, it also joined the base of the spinous processes (Fig. 4). In Type III, it was present also around the PEEK plate. In Type IV, fusion of even the facet joints had occurred (Fig. 5). Interlaminar fusion was not detected in any case. Significant differences were found for all outcome measures between the mean scores at baseline and those at last follow-up (Table 4). The mean NRS score decreased by $64.5 \%$ for low back pain and 

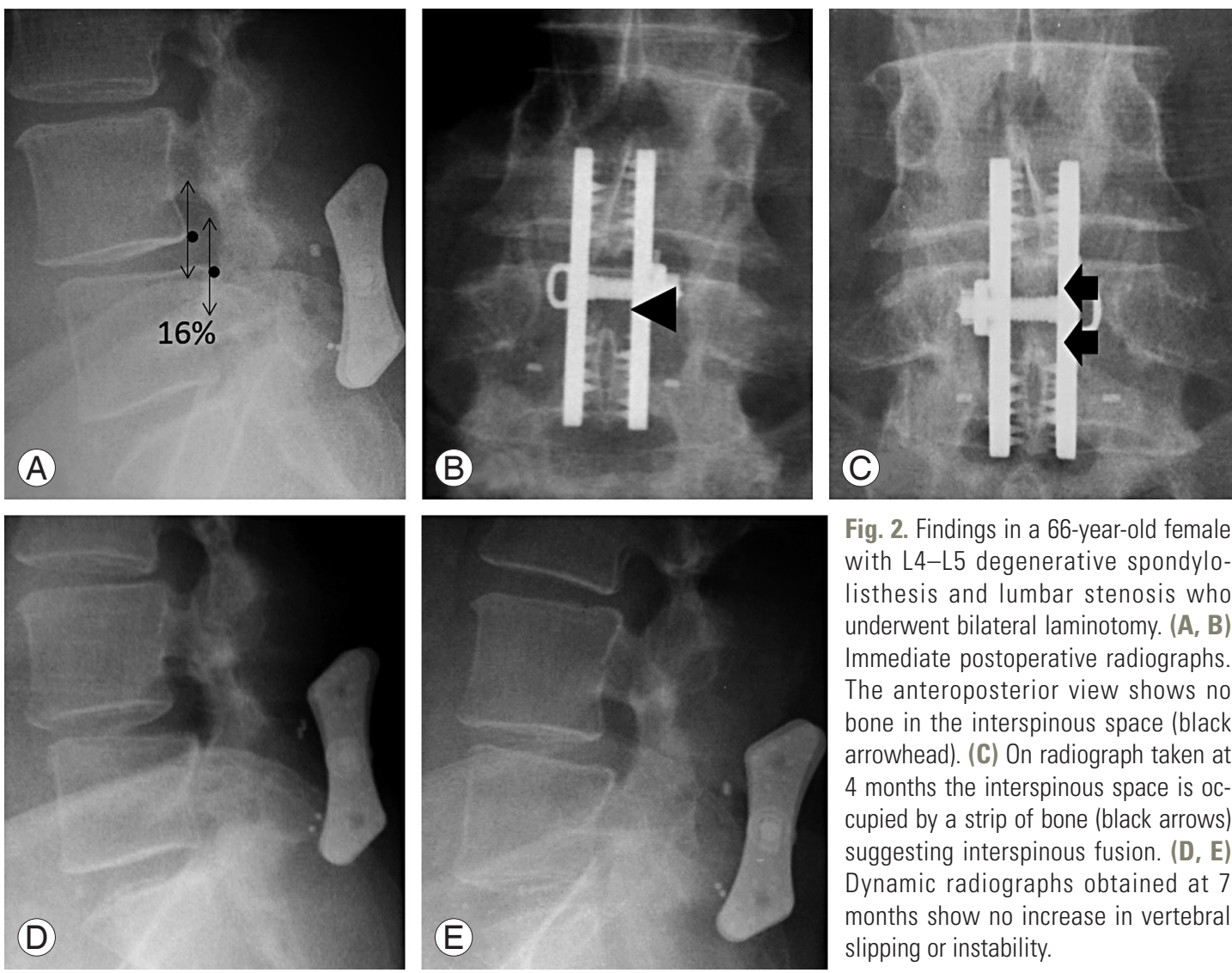

Fig. 2. Findings in a 66-year-old female with L4-L5 degenerative spondylolisthesis and lumbar stenosis who underwent bilateral laminotomy. (A, B) Immediate postoperative radiographs. The anteroposterior view shows no bone in the interspinous space (black arrowhead). (C) On radiograph taken at 4 months the interspinous space is occupied by a strip of bone (black arrows) suggesting interspinous fusion. (D, E) Dynamic radiographs obtained at 7 months show no increase in vertebral slipping or instability.
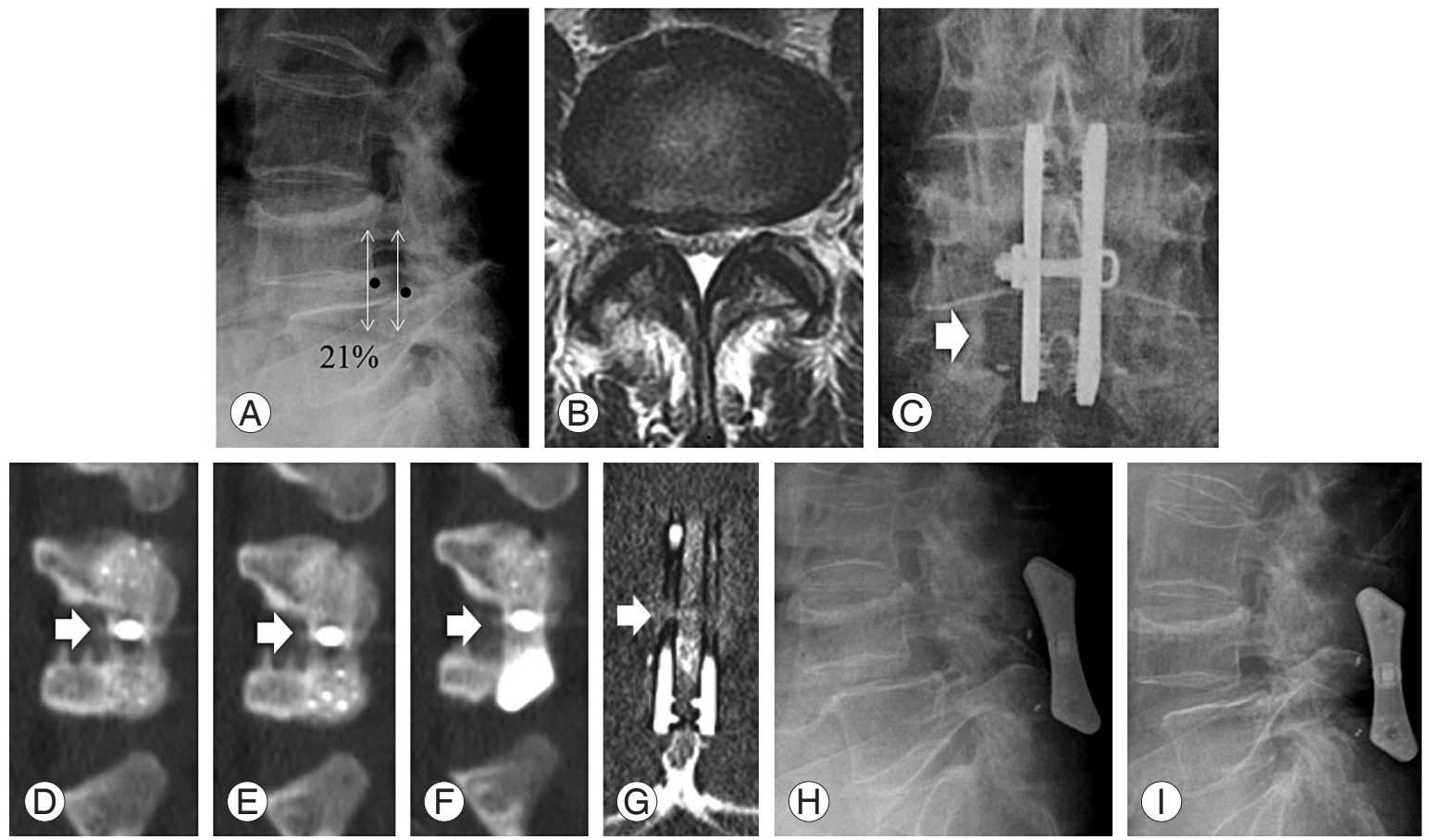

Fig. 3. A 61-year-old female with severe Grade I degenerative spondylolisthesis (A) and severe stenosis (B) underwent bilateral decompression by unilateral laminotomy on the right side (white arrow). After 4 months, the anteroposterior radiograph revealed an uncertain interspinous fusion (C), but at 7 months the reconstructed sagittal computed tomography scans (D, E, F) revealed fusion of the posterior half of the spinous processes (white arrows). The coronal scan (G), showing a strip of bone above the processes (white arrow), confirms the bony fusion. Postoperative dynamic radiographs showed no increase in olisthesis (H) or angular vertebral displacement (I). 

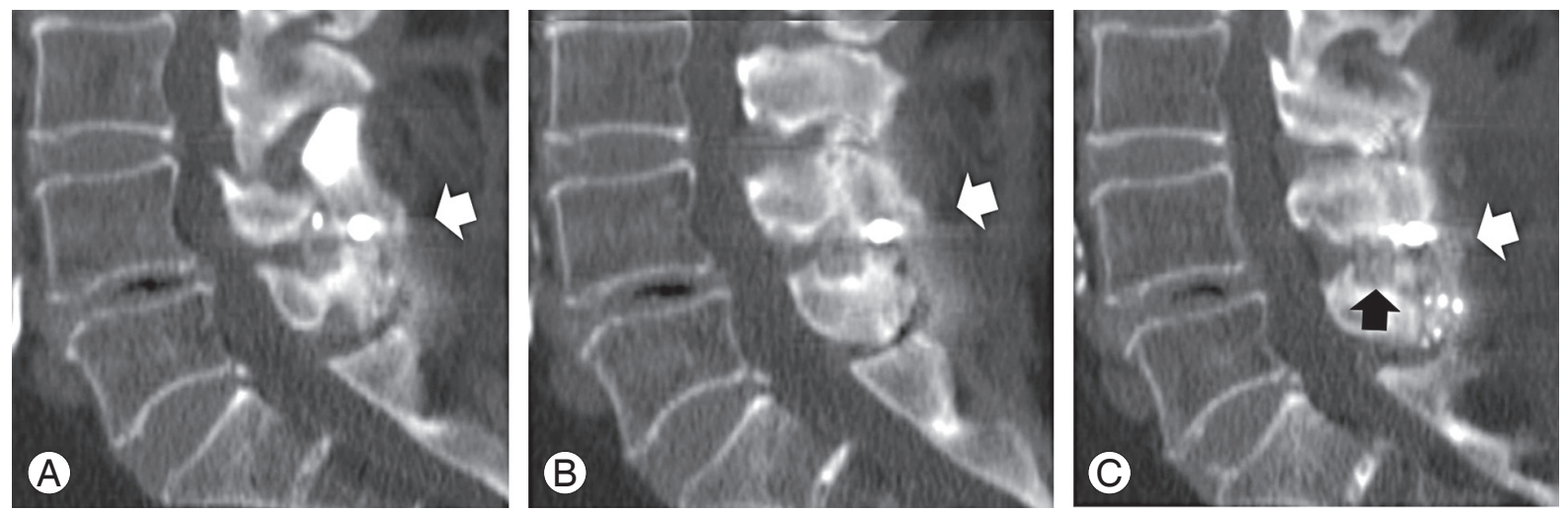

Fig. 4. A 63-year-old male with L4-L5 degenerative spondylolisthesis. (A, B, C) Sagittal computed tomography scans showing supraspinous and interspinous bone fusion (white arrows). Bone is present also between the base of spinous processes (black arrow).
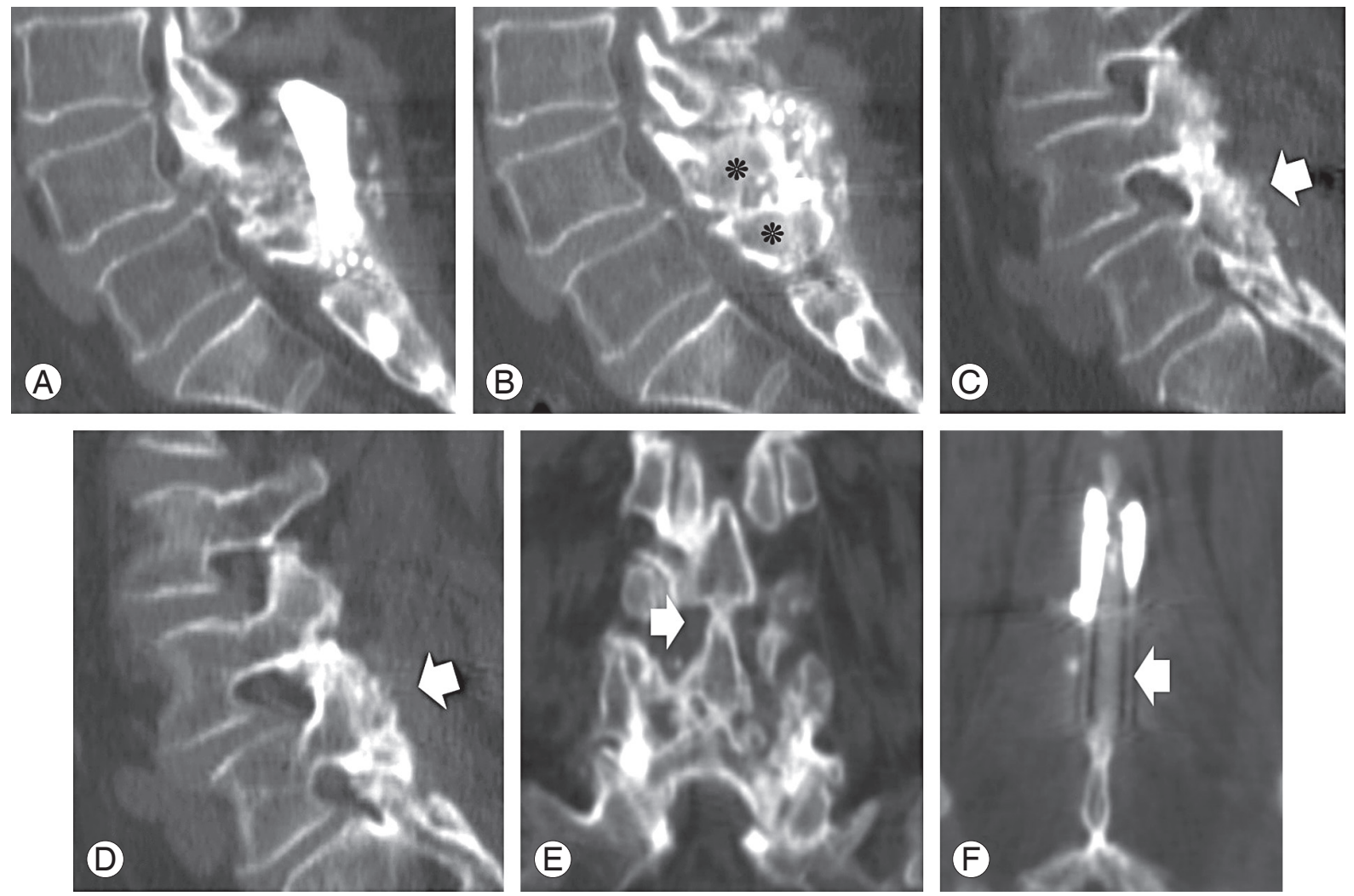

Fig. 5. A 62-year-old female with L4-L5 degenerative spondylolisthesis and lumbar stenosis. (A, B, C) Reconstructed sagittal and (E, F) coronal scans. The paramedian sagittal scan (A) shows newly formed bone dorsally and ventrally to the lateral plates of ILIF and the midsagittal scan (B) fusion of the spinous processes (asterisks), as well as abundant bone dorsally to the processes. (C, D) Demonstrate fusion of the right and left facet joint, respectively (white arrows). (E) Shows fusion of the base of the spinous processes (white arrow) and (F) a continuous strip of bone connecting the top of the processes (arrow).

$80.4 \%$ for leg pain. The mean ODI score diminished by $52.6 \%$. The mean SF-36 bodily pain and physical function scores increased by $53.7 \%$ and $58.9 \%$, respectively. The mean scores of all measures did not change significantly between the 12-month and last follow-up.

Of the four unfused patients, two had BL and two had
BDUL. Three patients who had mild $(\mathrm{n}=1)$ or moderate $(\mathrm{n}=2)$ slipping at baseline displayed no increase in olisthesis, whereas one patient with severe olisthesis who underwent BL exhibited an increase in slipping of $4 \%$. (Table 3 ). Preoperatively, sagittal instability was mild in one patient, moderate in two patients, and severe in one patient. The 
Table 4. Outcome measures in fused ad unfused patients

\begin{tabular}{|c|c|c|c|}
\hline Outcome & Baseline & Last follow-up & $p$-value \\
\hline \multicolumn{4}{|l|}{ Fused patients } \\
\hline NRS for LBP & $4.71 \pm 0.84(3.34-7.80)$ & $1.67 \pm 0.57(0.72-2.08)$ & 0.006 \\
\hline NRS for LP & $6.10 \pm 1.30(3.64-4.76)$ & $1.19 \pm 0.68(1.24-2.36)$ & 0.005 \\
\hline Oswestry disability index & $44.37 \pm 7.85(40.3-53.6)$ & $20.99 \pm 5.06(16.5-34.0)$ & 0.0001 \\
\hline SF-36 BP & $31.25 \pm 4.78(23.3-36.8)$ & $67.50 \pm 8.60(53.7-81.2)$ & 0.0002 \\
\hline SF-36 PF & $25.0 \pm 5.0(17.04-32.9)$ & $60.87 \pm 5.12(52.7-69.0)$ & 0.0002 \\
\hline \multicolumn{4}{|l|}{ Unfused patients } \\
\hline NRS for LBP & $4.4 \pm 1.40(4.36-8.04)$ & $3.4 \pm 0.54(1.84-4.46)$ & 0.11 \\
\hline NRS for LP & $6.2 \pm 1.48(2.98-5.82)$ & $3.2 \pm 1.09(2.72-4.08)$ & 0.04 \\
\hline Oswestry disability index & $38.75 \pm 12.52(18.8-58.6)$ & $20.5 \pm 5.0(1.50-28.4)$ & 0.30 \\
\hline SF-36 BP & $38.7 \pm 7.2(27.2-50.2)$ & $52.5 \pm 9.57(37.2-67.7)$ & 0.19 \\
\hline SF-36 PF & $38.75 \pm 4.78(31.3-46.3)$ & $62.5 \pm 11.9(43.5-81.4)$ & 0.06 \\
\hline
\end{tabular}

Values are presented as mean \pm standard deviation (95\% confidence interval).

NRS, numerical rating scale; LBP, low back pain; LP, leg pain; SF-36, 36-item short-form general health survey; BP, bodily pain; PF, physical function.

latter also had moderate dynamic angular motion. Postoperatively, the degree of instability changed from moderate to mild in the patient with incomplete fusion and was unchanged in the others. At last follow-up, the mean scores of the outcome measures were not significantly different from those at baseline, except for the NRS score for leg pain that showed a significant difference (Table 4). Statistical comparison between fused and unfused patients was not possible due to the small number of cases with failed fusion.

\section{Complications}

No intraoperative complications occurred. Postoperatively, there was no implant disassembly, migration or dislocation and no patients underwent repeat surgery.

\section{Discussion}

This study is the first demonstration that an interspinous fusion can be obtained with a stand-alone device in a condition like DS, in which the slipped vertebra may be stable, or unstable as it was in all our patients.

In recent decades, BL has become an alternative to laminectomy, associated or not associated with spinal fusion, in lumbar stenosis without or with DS $[17,18]$. In patients with DS, BL was typically employed in Grade I olisthesis with no or mild instability of the slipped ver- tebra. However, stenotic patients without or with DS undergoing $\mathrm{BL}$ were found to be at risk of increased vertebral slipping and dynamic translational instability after surgery [18]. More recently, BDUL has become the potential alternative to $\mathrm{BL}$, since it was found to provide a similar decompression on both sides of the spinal canal as BL $[19,20]$. Rampersaud et al. [21] used BDUL in patients with Grade I DS, no or mild mechanical back pain and no instability on dynamic radiographs. Likewise, other authors [22-25] performed BDUL in cases with Grade I DS and similar preoperative features. However, in three of the studies [23-25] there was a mean increase in vertebral slipping of $1.7 \%$ to $8.4 \%$ postoperatively and in the other study [21] $6.5 \%$ of patients required subsequent fusion at the decompressed level. In a study [26], in which BDUL was performed in patients with Grade I DS who had not or had instability preoperatively, the average slip increased by $0.7 \%$ and $5.4 \%$, respectively. It thus appears that both BL and BDUL may expose patients to a risk of increased vertebral slipping after surgery. This risk holds particularly for patients with dynamic translational motion of the olisthetic vertebra, in whom symptoms related to instability may worsen after operation.

In our series, the rate of solid fusion was $84 \%$ ( 21 of 25 cases), which compares well with the $87 \%$ found by Wang et al. [11] in 16 patients with no DS. Furthermore, it is also consistent with the results of studies on patients with DS undergoing not instrumented or instrumented pos- 
terolateral fusion [27], a PLIF associated with posterior instrumentation [28] or a mini-open TLIF with unilateral or bilateral pedicle-screw instrumentation [29].

In none of our patients with solid fusion plain radiographs showed increased vertebral slipping or instability of the slipped vertebra. Conversely, of the four patients with failed fusion, one had an increase in slipping and all still had vertebral instability on postoperative dynamic radiographs.

In fused patients, at last follow-up the mean NRS scores for back pain and leg pain had decreased by 3.0 and 4.9 points, respectively, compared to the baseline scores. The mean ODI had diminished by 23.3 points and the mean SF-36 bodily pain and physical function had increased, respectively, by 36.3 and 35.8 points, all differences being highly significant. In a study [24], the 28.9 points decrease in the mean ODI score in the group of patients undergoing BDUL with no fusion was similar to that found in our fused patients. However, in other investigations, the differences between preoperative and postoperative scores were considerably lower than ours. Sasai et al. [23] obtained a mean decrease of 12 points in the ODI and an improvement of back pain from moderate to mild in patients undergoing BDUL. Ghogawala et al. [22] compared decompression alone to decompression associated with posterolateral not instrumented fusion; the authors reported the mean ODI score to be decreased by 27.5 points in the fused patients and 13.6 in those unfused, and the mean SF-36 physical component summary to be increased by 15.9 and 6.5 points in the fused and unfused group, respectively. These findings indicate that interspinous fusion can yield good clinical outcomes, at least similar to those of traditional modalities of fusion.

The indications for fusion in patients with DS are still controversial. BDUL or BL performed without fusion give satisfactory clinical results [30]. However, a systematic review of the literature [31] revealed that satisfactory clinical outcomes are more likely to occur with fusion. This observation and the results of our study show that bony fusion, even if not strenuous as that provided by pediclescrew instrumentation, may be sufficient to improve the clinical results and avoid postoperative increase in olisthesis. The advantages of the interspinous fusion are that it is a minimally invasive procedure, implying a short operating time, little blood loss, and minor complications, if any.

Thus it is a procedure to be taken into account for Grade I DS with instability of the slipped vertebra, since it en- sures a sufficient vertebral stability in a high percentage of cases, as this study has shown, and avoids the drawbacks of both the decompression alone and the major types of fusion.

A limitation of this study is that there was no control group undergoing similar types of decompression with no ILIF implant. This is because in the study period all patients with chronic back pain exhibiting DS with dynamic instability underwent interspinous fusion and those with no or occasional back pain who had no ILIF were too few to allow valid statistical comparison with the study group.

\section{Conclusions}

ILIF implant associated with interspinous bone grafting provided vertebral fusion in most stenotic patients with Grade I DS undergoing BL or BDUL. At the 2-year followup, all patients with fusion who preoperative had chronic back pain exhibited a highly significant improvement in all outcome measures, indicating a satisfactory clinical result, and none had an increase in olisthesis, or showed instability of the slipped vertebra.

\section{Conflict of Interest}

No potential conflict of interest relevant to this article was reported.

\section{References}

1. Postacchini F. Management of lumbar spinal stenosis. J Bone Joint Surg Br 1996;78:154-64.

2. Amato V, Giannachi L, Irace C, Corona C. Accuracy of pedicle screw placement in the lumbosacral spine using conventional technique: computed tomography postoperative assessment in 102 consecutive patients. J Neurosurg Spine 2010;12:306-13.

3. Raley DA, Mobbs RJ. Retrospective computed tomography scan analysis of percutaneously inserted pedicle screws for posterior transpedicular stabilization of the thoracic and lumbar spine: accuracy and complication rates. Spine (Phila Pa 1976) 2012;37: 1092-100.

4. Okuda S, Iwasaki M, Miyauchi A, Aono H, Morita M, Yamamoto T. Risk factors for adjacent segment degeneration after PLIF. Spine (Phila Pa 1976) 2004;29: 1535-40. 
5. Kim TH, Lee BH, Moon SH, Lee SH, Lee HM. Comparison of adjacent segment degeneration after successful posterolateral fusion with unilateral or bilateral pedicle screw instrumentation: a minimum 10year follow-up. Spine J 2013;13:1208-16.

6. Kim HJ, Bak KH, Chun HJ, Oh SJ, Kang TH, Yang MS. Posterior interspinous fusion device for one-level fusion in degenerative lumbar spine disease: comparison with pedicle screw fixation: preliminary report of at least one year follow up. J Korean Neurosurg Soc 2012;52:359-64.

7. Karahalios DG, Kaibara T, Porter RW, et al. Biomechanics of a lumbar interspinous anchor with anterior lumbar interbody fusion. J Neurosurg Spine 2010;12:372-80.

8. Techy F, Mageswaran P, Colbrunn RW, Bonner TF, McLain RF. Properties of an interspinous fixation device (ISD) in lumbar fusion constructs: a biomechanical study. Spine J 2013;13:572-9.

9. Kim DH, Shanti N, Tantorski ME, et al. Association between degenerative spondylolisthesis and spinous process fracture after interspinous process spacer surgery. Spine J 2012;12:466-72.

10. Pradhan BB, Turner AW, Zatushevsky MA, Cornwall GB, Rajaee SS, Bae HW. Biomechanical analysis in a human cadaveric model of spinous process fixation with an interlaminar allograft spacer for lumbar spinal stenosis: laboratory investigation. J Neurosurg Spine 2012;16:585-93.

11. Wang S, Chao J, Wei J, Diaz FG. Short-term effectiveness of interlaminar lumbar instrumented fusion through a small incision for lumbar spinal stenosis. Zhongguo Xiu Fu Chong Jian Wai Ke Za Zhi 2012;26: 703-7.

12. Postacchini R, Ferrari E, Cinotti G, Menchetti PP, Postacchini F. Aperius interspinous implant versus open surgical decompression in lumbar spinal stenosis. Spine J 2011;11:933-9.

13. Dupuis PR, Yong-Hing K, Cassidy JD, Kirkaldy-Willis WH. Radiologic diagnosis of degenerative lumbar spinal instability. Spine (Phila Pa 1976) 1985;10:26276.

14. Postacchini F, Perugia D. Degenerative lumbar spondylolisthesis. Part I: etiology, pathogenesis, pathomorphology, and clinical features. Ital J Orthop Traumatol 1991;17:165-73.

15. Rousseau MA, Lazennec JY, Bass EC, Saillant G. Pre- dictors of outcomes after posterior decompression and fusion in degenerative spondylolisthesis. Eur Spine J 2005;14:55-60.

16. Anderson DG, Limthongkul W, Sayadipour A, et al. A radiographic analysis of degenerative spondylolisthesis at the L4-5 level. J Neurosurg Spine 2012;16: 130-4.

17. Aryanpur J, Ducker T. Multilevel lumbar laminotomies: an alternative to laminectomy in the treatment of lumbar stenosis. Neurosurgery 1990;26:429-32.

18. Hong SW, Choi KY, Ahn Y, et al. A comparison of unilateral and bilateral laminotomies for decompression of L4-L5 spinal stenosis. Spine (Phila Pa 1976) 2011;36:E172-8.

19. Iwatsuki K, Yoshimine T, Aoki M. Bilateral interlaminar fenestration and unroofing for the decompression of nerve roots by using a unilateral approach in lumbar canal stenosis. Surg Neurol 2007;68:487-92.

20. Choi WS, Oh CH, Ji GY, et al. Spinal canal morphology and clinical outcomes of microsurgical bilateral decompression via a unilateral approach for lumbar spinal canal stenosis. Eur Spine J 2014;23:991-8.

21. Rampersaud YR, Fisher C, Yee A, et al. Health-related quality of life following decompression compared to decompression and fusion for degenerative lumbar spondylolisthesis: a Canadian multicentre study. Can J Surg 2014;57:E126-33.

22. Ghogawala Z, Benzel EC, Amin-Hanjani S, et al. Prospective outcomes evaluation after decompression with or without instrumented fusion for lumbar stenosis and degenerative Grade I spondylolisthesis. J Neurosurg Spine 2004;1:267-72.

23. Sasai K, Umeda M, Maruyama T, Wakabayashi E, Iida H. Microsurgical bilateral decompression via a unilateral approach for lumbar spinal canal stenosis including degenerative spondylolisthesis. J Neurosurg Spine 2008;9:554-9.

24. Kelleher MO, Timlin M, Persaud O, Rampersaud YR. Success and failure of minimally invasive decompression for focal lumbar spinal stenosis in patients with and without deformity. Spine (Phila Pa 1976) 2010;35:E981-7.

25. Park JH, Hyun SJ, Roh SW, Rhim SC. A comparison of unilateral laminectomy with bilateral decompression and fusion surgery in the treatment of grade I lumbar degenerative spondylolisthesis. Acta Neurochir (Wien) 2012;154:1205-12. 
26. Jang JW, Park JH, Hyun SJ, Rhim SC. Clinical outcomes and radiologic changes following microsurgical bilateral decompression via a unilateral approach in patients with lumbar canal stenosis and grade I degenerative spondylolisthesis with a minimum 3-year follow-up. J Spinal Disord Tech 2012 Oct 15 [Epub]. http://dx.doi.org/10.1097/BSD.0b013e31827566a8.

27. Fischgrund JS, Mackay M, Herkowitz HN, Brower R, Montgomery DM, Kurz LT. 1997 Volvo Award winner in clinical studies. Degenerative lumbar spondylolisthesis with spinal stenosis: a prospective, randomized study comparing decompressive laminectomy and arthrodesis with and without spinal instrumentation. Spine (Phila Pa 1976) 1997;22:280712.

28. Tullberg T, Brandt B, Rydberg J, Fritzell P. Fusion rate after posterior lumbar interbody fusion with carbon fiber implant: 1-year follow-up of 51 patients. Eur Spine J 1996;5:178-82.

29. Choi UY, Park JY, Kim KH, et al. Unilateral versus bilateral percutaneous pedicle screw fixation in minimally invasive transforaminal lumbar interbody fusion. Neurosurg Focus 2013;35:E11.

30. Nakanishi K, Tanaka N, Fujimoto Y, et al. Mediumterm clinical results of microsurgical lumbar flavectomy that preserves facet joints in cases of lumbar degenerative spondylolisthesis: comparison of bilateral laminotomy with bilateral decompression by a unilateral approach. J Spinal Disord Tech 2013;26:351-8.

31. Martin CR, Gruszczynski AT, Braunsfurth HA, Fallatah SM, O’Neil J, Wai EK. The surgical management of degenerative lumbar spondylolisthesis: a systematic review. Spine (Phila Pa 1976) 2007;32:1791-8. 